\title{
Curso de Roteiro para Produção de Vídeo Estudantil: Perfil dos Professores
}

\author{
Josias Pereira $^{1}$, Eliane Candido ${ }^{2}$, Viviane Lino $^{3}$ \\ ${ }^{1}$ Centro de Artes - Universidade Federal de Pelotas (UFPel). R. Álvaro Chaves, 65 - \\ Centro, CEP 96010-760 Pelotas - RS - Brasil \\ ${ }^{2}$ Centro de Artes - Universidade Federal de Pelotas (UFPel). R. Álvaro Chaves, 65 - \\ Centro, CEP 96010-760 Pelotas - RS - Brasil \\ ${ }^{3}$ Centro de Artes - Universidade Federal de Pelotas (UFPel). R. Álvaro Chaves, 65 - \\ Centro, CEP 96010-760 Pelotas - RS - Brasil \\ josiasufel@gmail.com, eliane.candido21@gmail.com, \\ vivianepereslino@gmail.com
}

\begin{abstract}
The article presents and discusses the results of a script course for student video held in distance education for teachers of basic education in 2019. Data were collected in the course enrollment by course participants. It was discussed the transposition of a practical and poetic action for the distance learning modality. It was possible to detect the need for teacher training projects allied to the PVE methodology.

Resumo. $O$ artigo apresenta e discute resultados de um curso de roteiro para vídeo Estudantil realizado na modalidade EaD para professores da Educação básica no ano de 2019. Os dados foram coletados na inscrição do curso pelos cursistas. Discutiu-se a transposição de uma ação prática e poética para a modalidade EaD. Foi possível detectar a necessidade de projetos de capacitação docente aliados a metodologia PVE.
\end{abstract}

\section{Introdução}

A realização de um curso de roteiro para professores possibilita esse docente a produzir vídeos ou pensar roteiros dentro do seu espaço educacional. Vivemos uma realidade onde a produção de vídeo está dentro do espaço escolar, vide o número de festivais de vídeos estudantis existentes no Brasil. Um levantamento realizado pelo grupo de pesquisa "Produção de Vídeo Estudantil" e pelo Congresso Brasileiro de Produção de Vídeo Estudantil (CBPVE), site disponível em https://wp.ufpel.edu.br/cbpve/, sobre o número de professores produzindo vídeo detectou que em sua maioria mesmo sem ter base elementar para realizar este trabalho os professores fazem em função de mudar a sua didática. Essa ação nos motivou a realizar um curso de roteiro para professores que tem interesse em produzir vídeo com seus alunos.

Segundo dados do Congresso Brasileiro de Produção de Vídeo Estudantil existe no Brasil hoje em média 50 festivais de vídeo estudantis, específicos ou que aceitam vídeo feito por estudantes. Sendo assim, se existe um festival de vídeo é porque existem professores realizando vídeo dentro do espaço escolar. Se cada Festival apresenta em média 10 vídeos concorrendo temos por ano 500 vídeos sendo feito por 
alunos dentro do espaço escolar. E quem capacitou estes professores a realizarem vídeo com os alunos? Segundo Pereira e Mattos (2017) dos seis cursos de Pedagogia do Rio Grande do Sul pesquisados não apresentam disciplinas ligadas a produção de vídeo estudantil os mais próximos são os de tecnologia e mesmo os que apresentam a disciplina tecnologia são em sua maioria teóricas e não práticas.

Pensando em contribuir com esses professores iniciamos no ano de 2019 um curso totalmente on line para que fossem capacitados primeiro na teoria de como funciona um roteiro cinematográfico e em seguida com uma ação prática que ele poderia realizar dentro da sala de aula com os seus alunos. O nosso curso foi intitulado "Roteiro para Produção de Vídeo Estudantil" foi utilizado a plataforma institucional da Universidade Federal de Pelotas (UFPel) a plataforma Moodle. A criação desse curso se fez necessária em função do aumento dos festivais de vídeo estudantis no Brasil e do pedido de alguns professores sobre se a UFPel teria algum curso de especialização para capacita-los na produção de vídeo estudantil. Como a criação de um curso de Pósgraduação tem uma demanda institucional mais complexa preferimos então a criação de um curso com uma carga horária de $40 \mathrm{~h}$ para contribuir na capacitação deste professor.

\section{O Curso}

Sendo assim o nosso grupo de pesquisa cria o curso que objetiva e capacita o professor da educação básica. Para a inscrição realizamos um questionário e enviamos para escolas municipais que temos contato nos 9 anos do projeto de extensão e pesquisa e nos cadastrados no CBPVE. Em seguida colocamos nas redes sociais. Inicialmente o curso teria 100 vagas, pois achamos que o grupo poderia organizar esse número de professores. Como na primeira semana tivemos 300 inscritos e no fim da segunda semana chegamos ao número de quase 800 inscritos sendo assim os coordenadores preferiram aumentar o número de vagas para 327 contribuindo assim como os professores que desejam aprender a fazer vídeo. A seleção dos alunos para o curso foi uma etapa importante e para essa ação, conforme o edital de inscrição, foi levado em consideração os professores que NUNCA realizaram vídeo com seus alunos, justamente para capacita-los dentro desta ação. No questionário várias perguntas eram voltadas a conhecer o público alvo, porém as últimas eram destinadas a conhecer o professor e seus anseios na produção de vídeo estudantil. Essa questão foi colocada como última para justificar porque desejava fazer o curso de roteiro.

Criamos essa questão justamente para termos um material de análise sobre as dificuldades e importância do roteiro para professores da educação básica. Para nossa surpresa percebemos que muitas das justificativas eram justamente pautas de debates do grupo de pesquisa. Queríamos com esse curso além de capacitar o professor da educação básica compreender a área e aumentar a organização dessa ação dentro do espaço escolar. A realização de um curso de roteiro para professores da educação básica possibilita esse docente a produzir vídeos e pensar o roteiro dentro do seu espaço educacional vivemos na realidade onde a produção de vídeo está dentro de espaço escolar. 


\section{Decupando o Roteiro}

Os dados utilizados na análise e seleção dos alunos (professores) que se inscreveram para o curso de Roteiro para a Produção de Vídeo Estudantil foram obtidos junto ao formulário online (Google Forms) que os mesmos preencheram no ato de sua inscrição. Dentre vários quesitos perguntados, tais como, nome completo, e-mail, Cadastro de Pessoa Física (CPF), formação acadêmica, nível de ensino, tempo de docência, entre outros, destacamos três variáveis fundamentais para a seleção dos candidatos:

a) justificar a participação no curso de roteiro;

b) se já tinha realizado vídeo ou não (se sim, quantos vídeos);

c) e em qual estado brasileiro residia.

Após lermos e relermos o material do formulário de inscrição e definido as prioridades na seleção dos 327 candidatos pensamos em como disponibilizar ao leitor uma visão geral do universo da amostra com a finalidade de conhecer o público alvo do curso. Sendo assim, criamos alguns gráficos e tabelas que vão ilustrar melhor a realidade do curso de Roteiro para Produção de Vídeo Estudantil (RPVE), realizado no primeiro semestre de 2019, no Ambiente Virtual de Aprendizagem (AVA) Moodle da Universidade Federal de Pelotas (UFPEL).

Quanto a formação acadêmica dos professores/alunos selecionados percebemos maior incidência na pós-graduação (Figura 1) em quase todas as áreas do conhecimento que, segundo definição do CNPq, são: Ciências Exatas e da Terra, Ciências Biológicas, Engenharia / Tecnologia, Ciências da Saúde, Ciências Sociais, Ciências Humanas, Linguística, Letras e Artes. A única área não contemplada porque não havia nenhum inscrito foi a de Ciências Agrárias. A maioria dos graduados recai sob o curso de Pedagogia e dos pós-graduados nas áreas de Ciências Humanas e Linguística, Letras e Artes.

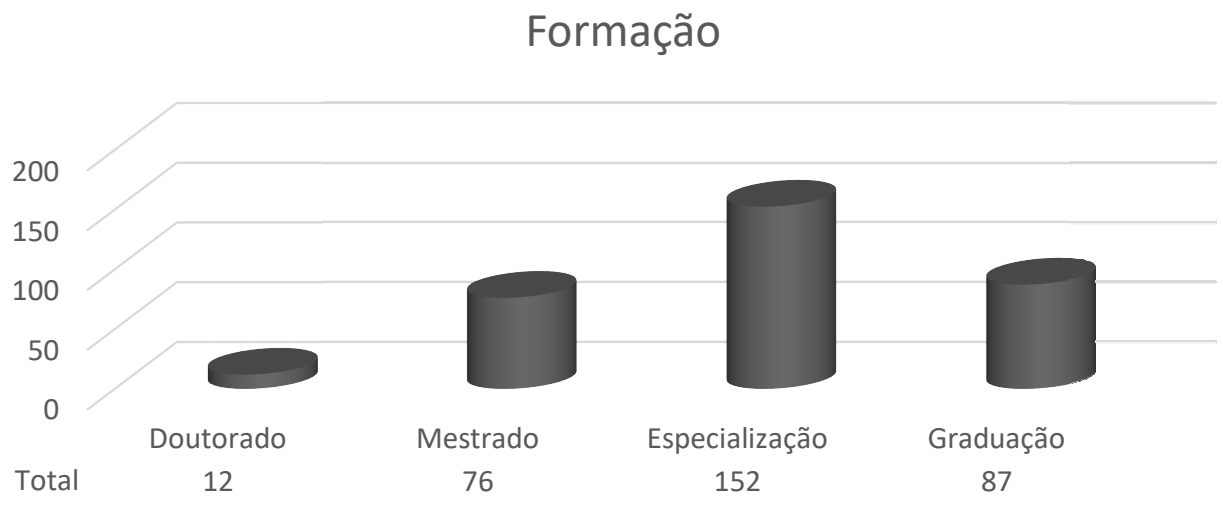

Figura 1. Formação acadêmica dos cursistas.

Outro dado dos professores que merece bastante relevância versa sobre o nível em que atuam na Educação Básica e o tempo de docência. 


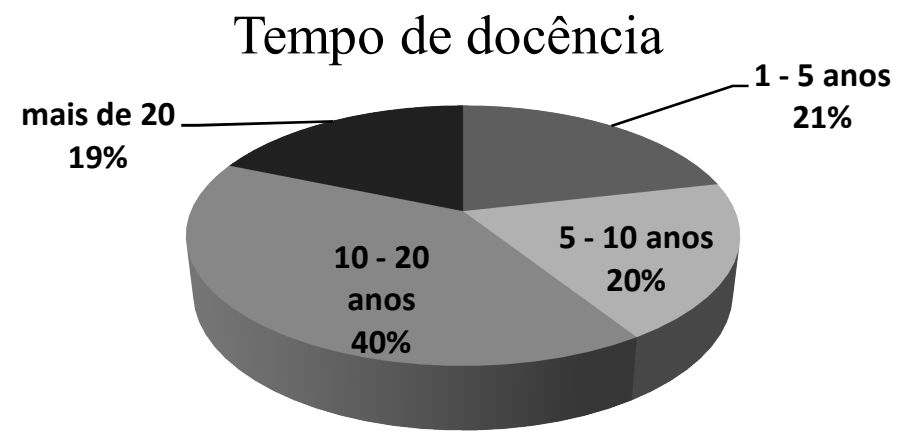

Figura 2. Tempo de atuação na Educação.

A maior parte dos selecionados trabalha no Ensino Fundamental (anos iniciais e finais, respectivamente) sendo que $40 \%$ possui entre 10 a 20 anos (Figura 2) de exercício na profissão. Isso demonstra a carência de uma formação continuada que dê conta de atualizar os professores às novas tendências contemporâneas e a preocupação que têm em aperfeiçoar a sua prática pedagógica e adequar-se aos avanços da sociedade, inclusive tecnológicos.

Segundo a Base Nacional Comum Curricular [BNCC, 2017] a formação continuada dos professores é algo imprescindível para atualização dos mesmos, sendo, portanto, uma pauta obrigatória dentro do espaço escolar. Porém, na realidade, sabemos que essas formações mal acontecem nas instituições de ensino. Por isso que o professor, muitas vezes, sai por conta própria em busca de algo atrativo aos seus olhos, do desconhecido, de algo de seu interesse ou naquilo que mais precisa de aperfeiçoamento. As mídias e as Tecnologias da Informação e Comunicação (TCIs) se encontram na faixa dos cursos procurados pelo educador, seja por ser algo emergente, seja porque os estudantes vivem este momento digital. Por outro lado, o fator falta de tempo dos educadores é algo preocupante, pois ao demonstrarem vontade e necessidade de aperfeiçoamento não dispõem de tempo para a realização de cursos de atualização. Foi neste sentido que pensamos em um curso totalmente a distância que visasse atender os professores com múltiplas jornadas de trabalho, mas que desejam adquirir outras competências para tornar suas aulas mais atrativas.

Após essa visão geral dos cursistas, retornaremos aos três requisitos fundamentais para a seleção dos candidatos ao curso de RPVE, no qual priorizamos o professor que fosse iniciante na produção de vídeo estudantil, que residisse em diferentes estados brasileiros e com base na justificativa que apresentou para fazer parte do grupo de alunos do curso de RPVE. Cabe ressaltar que, para preservar a identidade dos participantes, ao citarmos algumas justificativas faremos uso da denominação professor um, professor dois e, assim, sucessivamente, através da palavra professor seguida da numeração, por exemplo, Professor-01.

De acordo com a tabela 1 é possível constatar a abrangência do curso que teve participantes de 19 dos 27 estados brasileiros, sendo que a maior representação recorreu sob o estado do Rio de Janeiro, Bahia, São Paulo, Rio Grande do Sul e Pernambuco. Ficamos muito contentes com a participação de vários estados, inclusive daqueles mais distantes dos grandes centros. 
Tabela 1. Participantes por estado.

\begin{tabular}{|l|c|l|c|}
\hline \multicolumn{1}{|c|}{ ESTADOS } & ALUNOS & \multicolumn{1}{|c|}{ ESTADOS } & ALUNOS \\
\hline Alagoas & 01 & Minas Gerais & 17 \\
\hline Amazonas & 08 & Pará & 13 \\
\hline Bahia & 60 & Paraíba & 03 \\
\hline Ceará & 03 & Paraná & 06 \\
\hline Espírito Santo & 07 & Pernambuco & 24 \\
\hline Goiás & 01 & Rio de Janeiro & 83 \\
\hline Maranhão & 05 & Rio Grande do Sul & 28 \\
\hline Mato Grosso & 16 & Santa Catarina & 01 \\
\hline Mato Grosso do Sul & 01 & São Paulo & 47 \\
\hline \multicolumn{2}{|r|}{} & Tocantins & 03 \\
\hline \multicolumn{2}{|c|}{ Total Geral } & \\
\hline
\end{tabular}

Essa formação continuada que o professor busca é um passo muito importante para a melhoria da qualidade de suas aulas numa tentativa de resgatar o interesse dos estudantes pela escola, pelo professor e disciplina. O educador quando tem consciência de seu papel mediador no processo de aprendizagem, reconhece que a sua formação não termina na universidade, sente falta de uma formação continuada que o coloque à frente de situações desafiadoras e vai a busca de novos caminhos que deem significado ao seu fazer didático e pedagógico. Segundo Freire (1991, p. 58), "Ninguém nasce educador ou marcado para ser educador. A gente se faz educador, a gente se forma como educador, permanentemente, na prática e na reflexão da prática".

Com o intuito de contribuir para a formação na escrita de Roteiro para a Produção de Vídeo Estudantil selecionamos educadores que tinham pouca ou nenhuma experiência em fazer vídeos com seus alunos (Figura 3) e mesclamos com suas reflexões sobre a prática, que vinham acompanhadas do desejo de mudança ou com a finalidade de aperfeiçoar projetos que estavam apenas iniciando na instituição que trabalha. Freire (1996) faz um paralelo entre dois tipos de educadores: aquele que diz que não sabe, mas que pode e quer aprender e que ganha ao somar novos conhecimentos; e aquele que mente que sabe com receio de acharem que ele é um fracassado sem credibilidade e que perde a oportunidade de crescer.

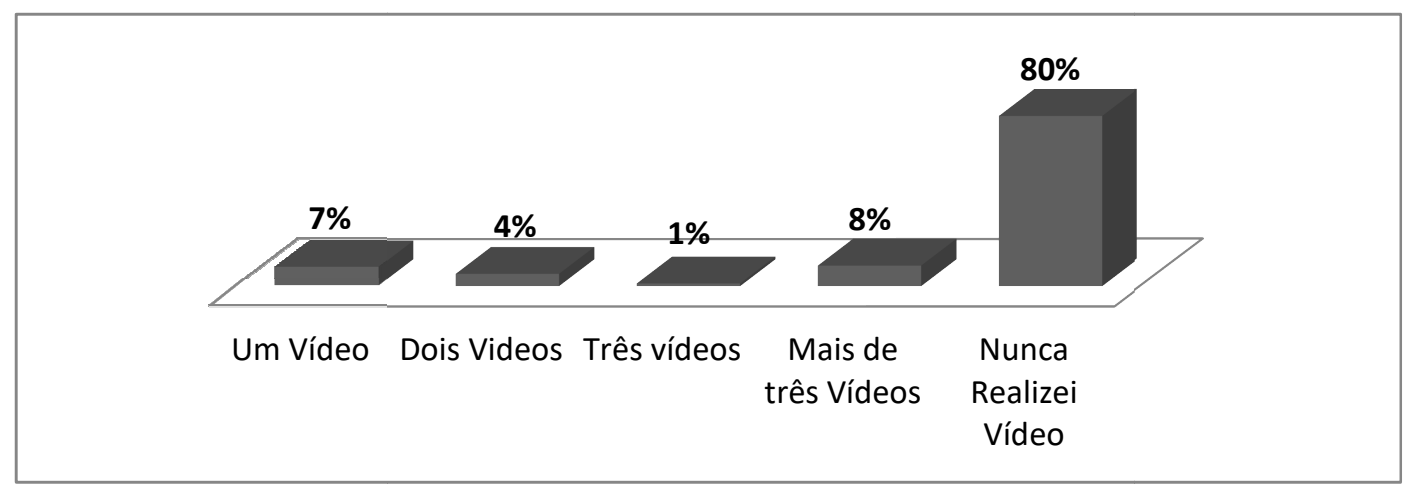

Figura 3. Educadores e a produção de vídeo realizado. 
Percebe-se que $80 \%$ dos professores, ou seja, a grande maioria dos cursistas disseram nunca terem realizado sequer um vídeo no contexto escolar, mas que, mesmo assim, queriam participar do curso para aprenderem, primeiramente, a criarem um roteiro de vídeo e, posteriormente, junto aos seus alunos, colocarem esta ideia em prática utilizando as etapas de construção de um vídeo ou curta-metragem: préprodução, produção e pós-produção. Na seção extra do curso no Moodle nós colocamos alguns vídeos com dicas de diversos professores colaboradores e apoiadores do curso de RPVE para que os professores/alunos pudessem ter uma noção de como darem continuidade as etapas de produção de vídeo estudantil.

Para finalizar este estudo vamos apontar as justificativas dos candidatos, requisito fundamental para a decisão da equipe coordenadora do curso, visto que havia quase o triplo de candidatos inscritos. Escolher um dentre outro foi uma obra de arte, pois o cruzamento das três variáveis - justificativas, produção de vídeo e o estado brasileiro em que vive - era imprescindível para chegarmos a um denominador comum. Cabe destacar que deixamos este requisito por último, porque o mesmo demanda de uma quantidade significativa de informações que contribuem para o fechamento desta análise. Contudo, na seleção dos candidatos este item foi o primeiro a ser observado e validado antes de prosseguirmos na análise dos outros dois aspectos.

Com o propósito de tornar a leitura deste artigo mais dinâmica, além de proporcionar ao leitor uma visão geral e ilustrativa das 327 justificativas na realização do curso de RPVE, criamos uma nuvem palavras (Figura 4), também conhecida como nuvem de tags, de nuvem de etiquetas, nuvem de palavras-chave ou nuvem de texto, utilizadas para categorizar de forma simples os termos que mais apareceram nos argumentos apresentados pelos professores selecionados ao curso. Segundo a Infogram (2019), disponível em <https://infogram.com>, a nuvem de tags é uma importante representação visual da quantidade e do valor das palavras presentes em um conjunto de dados. Nela o leitor pode obter insights imediatos sobre os termos mais importantes em nossos dados.

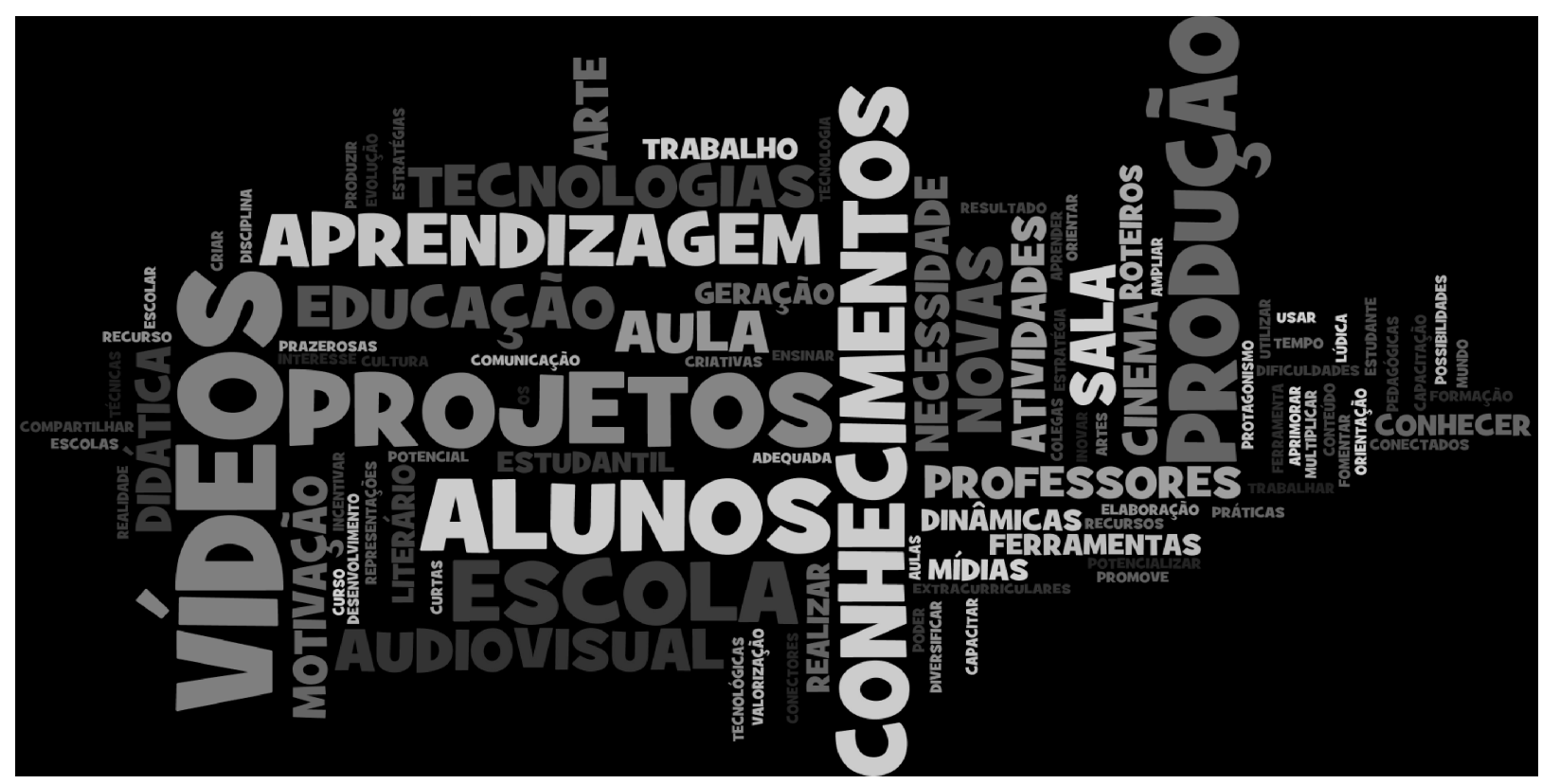

Figura 4. Nuvem de palavras-chave. 
Começaremos destacando as palavras da figura 4 que estão em tamanho maior e que, por consequência, foram aquelas que estiveram em maior evidência nas justificativas dos professores. Em seguida vamos dialogar sobre o conjunto de palavras que representam um ou mais conceitos, os teóricos que os sustentam e as declarações dos educadores.

Muitas justificativas evidenciaram o aperfeiçoamento profissional através da formação continuada para dar continuidade a projetos existentes na escola e/ou município, porém sentem a falta de profissionais preparados para trabalharem com a produção de vídeos com os alunos no espaço escolar. Outros expressaram a vontade de criar projetos nas suas aulas ou mesmo na instituição que leciona, em diversas áreas do conhecimento, por acreditarem que metodologias mais atrativas e condizentes com a realidade fazem parte deste contexto social, tecnológico, inclusivo, enfim com uma diversidade cultural que possa atender a todos de forma prazerosa. Neste sentido, destacamos alguns relatos que visam ratificar o que fora discutido até o momento:

Trabalho com projetos culturais, midiáticos, literários e cinematográficos no âmbito escolar e sinto muita dificuldade ao criar roteiros adequando-os às regras dos projetos estruturantes (artístico-literários) da Secretaria de Educação, principalmente o PROVE (Produção de Vídeos Estudantis) [...] Pretendo multiplicar esse conhecimento tanto no âmbito escolar quanto na rede de professores. [PROFESSOR-01, 2019].

Trabalho na sala de leitura de 2 escolas municipais e temos projetos que visam a produção de vídeos, no entanto nenhum dos professores têm capacitação para tal. Reconhecemos o potencial de nossos alunos para a produção audiovisual e gostaríamos de apoiá-los nas suas próprias produções. [PROFESSOR-02, 2019].

O Cinema e a Educação sempre despertaram o meu interesse. Apesar de ainda não ter realizado atividades de produção de vídeo, o Cinema já está presente nas minhas aulas de Espanhol, sendo uma das artes trabalhada com os alunos. [...] o curso seria de grande valor para ampliar meus conhecimentos, seja em sala de aula ou fora dela no desenvolvimento de projetos extracurriculares. [PROFESSOR-03, 2019].

Estou desenvolvendo um projeto chamado Causos da EJA, desejo produzir vídeos no qual os sujeitos explicitem suas trajetórias e seus saberes, objetivando o empoderamento e pertencimento ao retornarem a Escola, uma vez que trazem a marca da recente exclusão. [PROFESSOR-04, 2019].

Estou realizando um projeto na Sala de Recursos, onde o público alvo são os alunos da Educação Especial, sendo assim, a produção de vídeos com os alunos trará grande motivação no aspecto da inclusão. [PROFESSOR-05, 2019].

Este ano iniciei um projeto relacionado a criação e edição de vídeos, com um grupo de alunos surdos na escola onde leciono no município de São Bernardo do Campo e gostaria de obter uma formação direcionada a este assunto para aprimorar e qualificar minha prática. [PROFESSOR-06, 2019].

A partir dessas afirmações percebe-se que os educadores estão buscando alternativas que visam mudar o cenário de aulas tradicionais propondo a inserção das tecnologias no dia a dia da escola, ou seja, a produção de vídeos realizados pelos alunos através de projetos desenvolvidos no contexto escolar ou fora dele. Nesse sentido, Araújo (2003) defende o trabalho por projetos como uma estratégia pedagógica que propõe "a abertura para o novo; a perspectiva de uma ação voltada para o futuro, 
visando transformar a realidade; e a possibilidade de decisões, escolhas, apostas, riscos e incertezas." [ARAÚJO, 2003, p. 69].

Da mesma forma eles manifestaram a falta de preparo profissional e/ou de formação específica para trabalharem as tecnologias como apoio pedagógico, fato que os levou a se inscreverem no curso justificando tal carência encontrada no universo educacional. Para Charlot (2005, p.93) "formar é preparar para o exercício de práticas direcionadas e contextualizadas, nas quais o saber só adquire sentido com referência ao objetivo perseguido", portanto, de nada adianta uma formação continuada que não vá ao encontro dos anseios e desejo dos educadores.

Estes professores acreditam no potencial das tecnologias como uma fonte de informação e comunicação que vai além do caderno e lápis, é uma didática alternativa que envolve as relações humanas, uma aprendizagem construtiva e participativa, pautada na interação, na troca de experiências e opiniões, no respeito ao outro, entre tantos sentimentos que envolvem o ato de educar. Afinal, como já dizia Freire (1979), a educação é um ato de amor e de coragem, sustentada no diálogo, na discussão, no debate e na participação de todos, portanto a escola é um espaço privilegiado para o ensino e a aprendizagem entre os pares. Sendo assim, vejamos o que nossos cursistas declararam:

Tenho realizado vídeos com meus alunos, por acreditar que a autoria e o audiovisual trazem uma aprendizagem mais atraente e significativa[...] aprimorar o Projeto que desenvolvo no Instituto de Educação Rangel Pestana, com alunos do Curso Normal. [PROFESSOR-07, 2019].

Tenho um projeto, os Leitubers. Quero gravar vídeos incentivando a leitura na linguagem que eles mais utilizam. [...] Assim trabalharia a autoestima, oralidade, senso crítico e argumentação. [PROFESSOR-08, 2019].

Entender que a educação deve contribuir para a formação de alunos críticos, protagonistas e autônomos, que se vejam como produtores do próprio conhecimento e desenvolvam uma relação de pertencimento com os espaços de cultura. [PROFESSOR13, 2019].

Desafiar os alunos a se tornarem contadores de histórias, incentivando a necessidade de compartilhar sentidos e emoções. [PROFESSOR-14, 2019].

Gostaria de aprender a elaborar vídeos para poder criar conteúdos e desenvolver projetos com alunos para mostrar a realidade da sociedade e relacionar com a disciplina que ensino, a História. Também quero que a através desses vídeos meus alunos possam ser produtores e não só receptores do ensino, que eles percebam o potencial que têm e que são agentes históricos. [PROFESSOR-09, 2019].

Cada vez mais o mundo está aberto às novas linguagens. A escola (e o professor) deve apropriar-se delas e aproximar-se do mundo dos alunos, tornando-se mais dinâmica e estimulante. [PROFESSOR-10, 2019].

O aluno, ao ser protagonista dos seus registros, de suas produções, e percebendo na escola um lugar que incentiva e proporciona o uso das linguagens midiáticas, tende a criar um interesse e vínculo maiores com este espaço educacional. [PROFESSOR-11, 2019].

Eu teria a oportunidade de inverter a relação costumeira com os vídeos, ou seja, de meros espectadores e consumidores para efetivos realizadores e produtores. Com isto, também estaria se estimulando a autonomia dos estudantes, bem como trabalho 
colaborativo, através da resignificação de práticas que já realizam no cotidiano (gravar pequenos videos e postarem em redes sociais). [PROFESSOR-12, 2019].

Quero que os estudantes não só pensem o filme, mas façam filmes, que utilizem a linguagem da produção audiovisual para expressar seus sentimentos, angústias e seu mundo de vida. Que na era das imagens digitais eles saibam sistematizar suas ideias para usar como ferramenta de resistência e identidades infanto-juvenis. [PROFESSOR$15,2019]$.

Poderíamos tecer páginas e páginas de depoimentos riquíssimos e cheios de esperanças dos professores ao justificarem a vontade de fazerem o curso de roteiro. Porém, seria inviável descrever todas as 327 justificativas dos participantes que resultaram em 9.762 palavras dispostas em frases, sentenças e parágrafos argumentativos. Tampouco foi possível contemplar todos os termos na nuvem de palavras (Figura 4), apenas ressaltamos aquelas de maior valor expressivo para representar uma compilação de concepções sobre as temáticas: vídeo estudantil, roteiro, produção, didática, aprendizagem, formação e educação.

\section{Para não Finalizar}

Embora possa parecer dicotômico, mas educandos e educadores possuem desejos semelhantes, objetivam serem sujeitos melhores e almejam um mundo mais justo com oportunidades iguais para todos. Nós, seres humanos, somos agentes transformadores por natureza - do espaço em que vivemos e, consequentemente, da sociedade; somos críticos, pensantes, emocionantes, enfim, somos seres sociais aprendentes e ensinantes que no convívio, na interação e na troca com o outro crescemos e produzimos conhecimentos. E a produção de vídeo estudantil pode ter essa função de colaboração entre discente e docente, mas principalmente deixando o discente como agente do seu saber como apregoa algumas teorias como a da metodologia ativa que é o que a Produção de vídeo faz desde a sua gênese, deixar o aluno ativo na busca do seu aprendizado. Precisamos capacitar o docente nas ferramentas digitais disponíveis para sua melhor ação didática dentro do espaço escolar aliadas a BNCC.

Para essa ação nos últimos 10 anos realizamos oficinas, videoaulas, webseries, uma revista eletrônica e um congresso sobre produção de vídeo estudantil com o objetivo de compreender essa ação, técnica e pedagógica, de produzir video dentro do espaço escolar. Com esses dados desenvolvemos em conjunto com os professores a metodologia PVE (Produção de Vídeo Estudantil) que consiste em estabelecer caminhos, não regras, para realizar produção de vídeo de forma pedagógica. A metodologia PVE como toda metodologia estuda e apresenta métodos e não regras para uma pesquisa ou um estudo sistemático no nosso caso o objetivo é a criação de um produto a obra audiovisual realizada pelos alunos, mas pedagogicamente o intuito primordial é o processo de aprendizagem de uma realização prática, o vídeo. Como toda ação prática existe etapas que necessitam ser realizadas para que a obra audiovisual seja realizada, porém, essas regras dentro do espaço da arte e do espaço escolar não são segmentos postos e obrigatórios, mas caminhos que possuem atalhos onde a poética e a linguagem audiovisual se fazem necessários. Como trabalhamos com a produção audiovisual dos alunos, percebemos que é o momento que eles estão ativos dentro do processo educacional, sendo assim defendemos que essa produção audiovisual é uma metodologia ativa e pode ser aliada a BNCC dentro da ação pedagógica e didática 
docente. Este curso de roteiro para produção de vídeo estudantil foi o primeiro passo realizado pelo LabPVE no desenvolvimento da metodologia PVE.

\section{Referências}

Araújo, Ulisses F. (2003) “Temas transversais e a estratégia de projetos”. São Paulo: Moderna.

Brasil. (2020) Ministério da Educação. Secretaria da Educação Básica. "Fundamentos pedagógicos e estrutura geral da BNCC”. Brasília, DF, 2017. Disponível no portal do MEC.

Charlot, Bernard. (2005) "Relação Com o Saber, Formação de Professores e Globalização: Questões Para Educação Hoje”. Porto Alegre: Artmed.

Freire, Paulo. (1991) “A Educação na Cidade”. São Paulo: Cortez.

Freire, Paulo. (1979) "Educação e Mudança”. 12a Edição. Paz e Terra. Rio de Janeiro.

Freire, Paulo. (1996) "Pedagogia da autonomia”. São Paulo: Paz e Terra.

Pereira, Josias; e Mattos, Daniela Pedra. (2017) "A Produção de Vídeo na Prática Escolar: Análise do I Festival de Vídeo Estudantil da Cidade de Capão do Leão/RS Brasil”. In Revista Tecnologias na Educação -Ano 9 -Número/Vol.19 -Julho 2017. Disponível no link. http://tecedu.pro.br/wp-content/uploads/2017/07/Art13-vol19julho2017.pdf. 